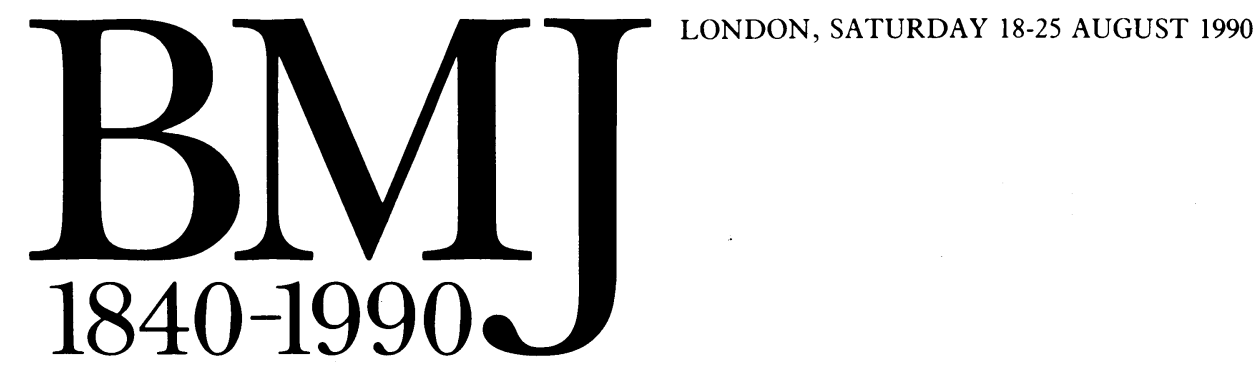

\title{
Poverty and health in the 1990s
}

\author{
Cliché it may be, but Disraeli's two nations are still around
}

The task of medicine is to promote health, to prevent disease, and to treat the sick. ... These are highly social functions.

\section{H E Sigirist $(1943)^{1}$}

Governments, just like private citizens, try to avoid public embarrassment. For the present British government one recurrent source of embarrassment must be the contrast between the rich and the poor in Britain. Ten years ago this month the report of the Research Working Group on Inequalities in Health-the Black report-was published reluctantly by a government that had not set up the working party and did not like its findings. ${ }^{2}$ The Secretary of State for Health, Patrick Jenkin, did his best to minimise publicity for the report: instead of publication by HMSO it was simply duplicated and 260 copies were made available at the August bank holiday weekend. In his foreword Patrick Jenkin refused to endorse the report's recommendations, arguing that additional expenditure on the scale suggested was "quite unrealistic in present or any forseeable economic circumstances."

Sir Douglas Black and his colleagues had documented the disparities in health - from birth onwards - among the social classes in Britain and the lack of any improvement throughout the 1960 s and 1970s. They recommended substantial government intervention to abolish child poverty, to provide children with free milk and free school meals, investment in day care and antenatal facilities and in home help and nursing services for the disabled; more spending on local authority housing; and a wide ranging programme of data collection and research into the causes of social inequalities in health.

The government's rejection of these proposals was predictable; they were exactly the sort of "socialist state interventions" it was pledged to oppose. Its justification was that each citizen's health was his or her own responsibility, that its own policies would lead to greater national prosperity, and that the increases in personal wealth would "trickle down" to reach all sectors of society. Indeed throughout the 1980s the government repeatedly asserted that the poor had become progressively better off since the Conservative party had come to power in 1979. But the assertion that the poor shared in the rise in general living standards in the 1980s has now been totally refuted in a report from the Department of Social Security. ${ }^{3}$

In a rerun of the low key release of the Black report in 1980 the report on households below average income appeared on a Monday evening in July, when the news bulletins were already full with details of a ministerial reshuffle. ${ }^{+}$Nevertheless the findings of the Government Statistical Service were unequivocal. From 1981 the average income for the whole population rose by over $20 \%$, but the bottom $10 \%$ saw their real income rise by only half the average. The number of people living on less than half the average income-the accepted measure of poverty - has risen to $7 \cdot 7$ million, and as the gap between the rich and the poor in Britain has widened half our children now live in poverty.

What has all this to do with medicine? To return to Sigirist. We understand only imperfectly the social causes of ill health, but in every country in the world the rich are healthier than the poor. As the poverty gap in Britain has widened so have differences in health become more striking. On p 373 Dr George Davey Smith and colleagues review the data that have been collected since the Black report and document the growing differences in both mortality and morbidity. ${ }^{5}$ Anyone tempted to dismiss these data as being due to the growth of a feckless underclass of work shy dropouts and drug addicts should examine them more closely. The mortality of people who do not own their homes or have the use of a car is higher than that of families with both - but the recent data also show that people who own two cars are healthier than those who own only one. Within the civil service the higher the individual's grade the better his or her health seems to be. The richer people are, it seems, the healthier they are, too. Part of the explanation comes from variations in risky behaviour such as cigarette smoking, but, in Davey Smith's words, "Studies in differential mortality reiterate the fact that British society is stratified to a fine grain from top to bottom."

The familiar verdict that more research is needed clearly applies here; but in practical terms much could be done to improve the overall health of the British population in the 1990s. A twofold strategy will be required: firstly, a determined effort will be needed to reverse the progressive impoverishment of the poorest people in Britain; and, secondly, the specific health recommendations in the Black report should be dusted off and re-examined.

Interventions by local authorities and by the national government may be anathema to many politicians, but their value is being recognised even in countries such as the United States, where there is growing concern about the poverty in which one quarter of that country's children live. Investment in antenatal care, infant nutrition, and infant education has been proved to be effective in improving health and possibly also in maximising each child's potential in intelligence. ${ }^{6}$ The 
results of several generations of high tax, high welfare policies may be seen in Scandinavia, where disparities in both wealth and health are much less sharp than in Britain and the United States.

What it comes down to, in the end, is that the poor are likely to remain unhealthy so long as they remain poor; conversely, the way to improve their health is to improve their economic state. Politicians who claim to care about the disparities in health in our society are being disingenuous if they deny the association with poverty. Eliminate poverty and health improves; everyone acknowledges that as a truth for the inhabitants of Third World shanty towns. What recent research in social medicine has now shown is that health continues to improve progressively as people get wealthier. If we care about the health of the poor we need to abolish their poverty.

Associate editor, $B M \mathcal{F}$ 1 Sigirist HE. Civilization and disease. Chicago: University of Chicago Press Phoenix Edition,
$1962: 241$. (First published Cornell University Press, 1943.)
2 Black D, Morris JN, Smith C, Townsend P. Inequalities in health: the Black report. Harmondsworth:
Penguin, 1982. (First published by the DHSS, 1980. New introduction by P Townsend and
N Davidson.)
3 Department of Social Security. Households below average income. A statistical analysis $1981-7$.
London: Government Statistical Service, 1990 .
4 Philips M. Statistics and the poverty of integrity. Guardian 1990 July $27: 19$ (cols $7-8$ ).
5 Smith GD, Bartley M, Blane D. The Black report on socioeconomic inequalities in health: 10 years
on. Br Med f 1990;301:373-7.
6 Martin SL, Ramey CT, Ramey S. The prevention of intellectual impairment in children of
impoverished families: findings of a randomized trial of educational day care. Am f Public Health
1990;80:844-7.

\section{Hereditary (primary) haemochromatosis}

\section{A common condition in which early recognition may be life saving}

Haemochromatosis is characterised by a substantial increase in total body iron concentration leading eventually to damage to organs such as the liver, heart, and islets of Langerhans in which the iron is deposited. ${ }^{1}$ The body has a limited capacity to excrete iron-some $1-2 \mathrm{mg}$ is lost daily, mainly in the urine-and normally intestinal iron absorption is limited to that required to maintain a normal total body iron concentration (3-4 g) by mucosal regulating mechanisms. ${ }^{2}$ Haemochromatosis may result from excessive oral iron intake, from excessive intestinal iron absorption, or from parenteral iron administration. In hereditary (primary) haemochromatosis a prolonged modest increase of iron absorption leads eventually to the accumulation of huge amounts of iron in the body (20$40 \mathrm{~g}$ ). The mechanism for this is unknown, but an inability to reduce iron absorption as the total body iron concentration increases is probably important. ${ }^{3}$

Sheldon provoked considerable controversy when he suggested more than half a century ago that this disease was inherited, ${ }^{4}$ but his view has been substantiated. Hereditary haemochromatosis is closely associated with the HLA-A3 antigen and to a lesser extent with the HLA-B14 antigen, and a study of HLA genotypes in patients and their siblings has shown that clinically manifest disease depends on the presence of two alleles (the hereditary haemochromatosis gene), pointing to a recessive mode of transmission. ${ }^{5}$ The responsible alleles are on the short arm of chromosome 6 . Heterozygotes have an increased intestinal iron absorption but do not absorb enough to develop disease unless a cause of secondary haemochromatosis is also present. ${ }^{67}$ The haemochromatosis gene is closely associated with the HLA-A3 gene but is not identical with it as the disease can occur with other HLA alleles and the mechanism whereby the putative haemochromatosis gene increases iron absorption remains unknown. Estimates of the frequency of the gene in white people in Europe $^{89}$ and North America ${ }^{10}$ give a figure of approximately 0.006 , making this one of the most common genetic abnormalities. This figure implies that about $11 \%$ of white people are heterozygotes and about $0.5 \%$ are homozygotes.

Because, then, hereditary haemochromatosis is so relatively common clinicians should increase their diagnostic awareness of the disease. Chronic liver disease should not be categorised as being of unknown cause until haemochromatosis has been excluded, and it is important that it can occur in both sexes and even in children." Modest hepatic siderosis occurs in alcoholics with liver disease, but considerable iron deposition in the liver is due to hereditary haemochromatosis and not a consequence of the alcoholism. ${ }^{12}$ Furthermore, a patient with early symptomatic haemochromatosis is more likely to present with constitutional symptoms such as weakness and lethargy or with extrahepatic features such as arthralgia than with classical features such as pigmentation; cirrhosis, and diabetes mellitus (bronze diabetes), which represent advanced disease. ${ }^{131+}$

Asymptomatic close relatives of patients with hereditary haemochromatosis, particularly siblings, should be advised to undergo investigation. Measurements of the serum ferritin and iron concentrations and saturation of serum iron binding capacity are used to detect iron overload in the first instance; measurement of liver iron concentration (which gives the most unequivocal evidence) requires liver biopsy and is too invasive for screening. In practice the results of these tests are always abnormal in patients presenting with clinical features of haemochromatosis, with ferritin concentrations usually above $1000 \mu \mathrm{g} / \mathrm{l}$ and the saturation of the iron binding capacity above $60 \%{ }^{14}$ The reliability of these tests is-as might be expected-less in healthy people who have not yet developed symptoms: in such people the saturation of the iron binding capacity after an overnight fast looks to be the most useful indicator; values above $60 \%$ are associated strongly with iron overload. ${ }^{115}$ Determination of HLA state may also be used to investigate siblings of patients, as those who are HLA identical with the patient are almost certainly homozygous for the haemochromatosis gene and therefore at risk of developing the disease. Determining the HLA state is not used for general screening because it would miss about a third of people at risk as the HLA-A3 antigen is found in only $70 \%$ of patients with the disease (as well as in $28 \%$ of the general population). Furthermore, HLA testing is expensive.

How far, however, does early identification benefit those found to have hereditary haemochromatosis? There is good evidence that venesection has improved their outlook, even though controlled studies have not been done. A recent retrospective study confirmed the beneficial effects of venesection, particularly in patients who had not developed diabetes mellitus. Patients who had not developed cirrhosis had a life expectancy identical to that of the general population. ${ }^{14}$ The major cause of death in patients with hereditary haemochromatosis who have been treated successfully is 